\title{
Dark adaptation in early primary biliary cirrhosis
}

\begin{abstract}
Background The role of vitamin $\mathrm{A}$ in early primary biliary cirrhosis $(\mathrm{PBC})$ remains uncertain.

Methods We assessed dark adaptation and assayed vitamin-A-related compounds in $\mathbf{1 0}$ patients with early PBC and a group of ageand sex-matched controls.
\end{abstract}

Results In patients compared with controls: (i) mean final light threshold value was $11.8 \%$ greater $(p<0.004)$, (ii) time taken to see the first light stimulus was longer $(2.8 \pm 0.6$ vs $1.4 \pm 0.2$ min, mean $\pm \mathrm{SEM} ; p<0.03$ ) and (iii) sensitivity to light stimuli was impaired after $6 \mathrm{~min}$ in the dark $(p<0.03)$. Three patients had an abnormal final light threshold despite receiving regular vitamin $A$; two had a low serum vitamin $A$. Raised serum bilirubin and increased age were the most important determinants of impaired dark adaptation. Conclusions Patients with early PBC have modestly impaired dark adaptation, despite standard vitamin A supplementation, although these changes may not have a significant effect on visual function. Vitamin A supplementation should be recommended for older patients with jaundice, but its effect should be carefully monitored.

Key words Primary biliary cirrhosis, Vitamin A, Dark adaptation, Light threshold, Bilirubin

Primary biliary cirrhosis (PBC) is an uncommon disorder, caused by progressive destruction of intrahepatic bile ducts leading to cholestasis and chronic liver disease. Vitamin A deficiency in PBC is well recognised ${ }^{1,2}$ and may lead to impaired dark adaptation ${ }^{3}$ and symptomatic night blindness ${ }^{3}$ with electrophysiological abnormalities. ${ }^{1}$ This has led to the widespread use of vitamin A replacement therapy to prevent such complications. ${ }^{4,5}$ However, the frequency of impaired dark adaptation in patients with $\mathrm{PBC}$ remains uncertain, with some authors claiming that this is a common problem $^{4}$ while others have found it to be infrequent. ${ }^{1}$ Furthermore, the role of prophylactic vitamin A replacement therapy in the prevention of impaired dark adaptation is unclear, particularly if the overall frequency of subclinical impaired dark adaptation is as low as suggested by some authors. ${ }^{1}$ Thus, the aims of the present study were to determine whether patients with early PBC had any evidence of impaired dark adaptation and to assess the role of vitamin A therapy in the prevention of night blindness.

\section{Materials and methods \\ Patients}

Ten female PBC patients, with a mean ( \pm SEM) age of $62.8 \pm 3.2$ (range $45-74$ ) years and diagnosed $7.8 \pm 1.7(0.8-14)$ years previously, were asked to participate in the study. The mean duration of symptomatic disease was $9.4 \pm 1.8(2.3-14.8)$ years. All patients had liver biopsy specimens consistent with a diagnosis of $\mathrm{PBC}^{6}$ and anti-mitochondrial antibody titres of more than 1:128. The severity of chronic liver disease was classified according to the Child-Pugh system. ${ }^{7}$ Eight patients were Child-Pugh class A and two class B (scores 6 and 7 respectively). The mean serum albumin was $37 \pm 2 \mathrm{~g} / \mathrm{l}$ and bilirubin $29 \pm 12 \mu \mathrm{mol} / \mathrm{l}$. Two patients previously had ascites associated with variceal bleeds, but at the time of the study had well compensated chronic liver disease. Patients with severe Child-Pugh B and C disease were excluded from selection. No patients had symptoms of night blindness. Three patients had complained of dry or gritty eyes and one patient complained of watery sore eyes.

Vitamin A intramuscular injections had been given on a monthly basis to 7 of the 10 patients at a dose of 100000 units per month for $4.3 \pm 1.6$ $(0.8-11)$ years. Six patients had received vitamin D supplements for $4.2 \pm 1.9(0.8-11)$ years. Ursodeoxycholic acid therapy was administered to 9 patients for $1.5 \pm 0.4$ years. Three patients had received cholestyramine for $1-14$ years.

\section{Controls}

The eight control subjects were all women recruited from members of staff and routine attenders at eye clinic without a history of liver disease. The mean age of this control group was $50.1 \pm 4.1$ (31-64) years, which was not statistically different from that of the patients studied. One control had unilateral mild amblyopia, and one complained of gritty eyes. All controls had normal haematology and biochemistry.
S.H. Hussaini M.S. Losowsky Academic Division of Medicine

Level 7

Clinical Science Building St James's University Hospital Leeds LS9 7TF, UK

Tel: +44(0)1132065256

Fax: $+44(0) 1132429722$ e-mail:

s.h.hussaini@leeds.ac.uk

T. Henderson

A.J. Morrell

Department of

Ophthalmology

St James's University Hospital

Leeds, UK 


\section{Assays}

A haematological and biochemical screen was performed on patients and controls. Serum beta-carotene, vitamin A and vitamin $\mathrm{E}$ assays were performed by standard fluorimetric techniques as described by Stewart and Fleming. ${ }^{8}$ Retinal binding protein (RBP) was assayed using an established radial immunodiffusion method. ${ }^{9}$

\section{Ophthalmic assessment}

All patients underwent fundoscopy and had visual acuity assessed using standard Snellen charts. Ishihara isochromatic colour plates were used to assess colour vision.

\section{Dark adaptation}

Patients and controls underwent dark adaptometry using a Friedmann visual field analyser. Dark adaptation was carried out in a 'blacked out' room with light seals around the doors and windows. Patients and controls had their pupils dilated before the dark adaptation test was performed. The individuals were seated, looking directly ahead, with the chin supported on a rest. A neon flash bulb light source from a circular diffuser (subtending an angle of $60^{\circ}$ ) with a DA3 dark adaptation filter (a 3 log neutral density filter) was used as the dark adaptation stimulus. The test eye was aligned with the centre of the stimulus bowl, and the other eye occluded with a sterile eye pad and shield. A modified photographic flash (Nikon SB15 speedlight) with an output stimulus equivalent to $\mathrm{f} 64.4$ at 100 ASA was used to perform light adaptation.

The minimum light intensity seen by a subject was recorded if three successive stimuli were seen, with the failure to see three subsequent stimuli when the filter density was increased by $0.2 \mathrm{log}$ units. The initial light threshold was determined by a light stimulus every 5-10 s with an immediate repeat stimulus to confirm the threshold value. Subsequent stimuli were presented every minute for the first $10 \mathrm{~min}$, in an attempt to determine the cone adaptation component and rod-cone break of the dark adaptation curve. Thereafter, stimuli were applied every $5 \mathrm{~min}$, to elicit the rod component of the dark adaptation response, until three successive light threshold values were the same, indicative of a final threshold value. Thus for some patients testing continued beyond 35 min to confirm that a final threshold had been reached. The entire procedure was then repeated for the other eye.

The dark adaptation curves were then analysed to determine:

(i) initial light threshold values measured in log candela per square metre $\left(\log \mathrm{cd} / \mathrm{m}^{2}\right)$ during dark adaptation (i.e. sensitivity to low light illumination);

(ii) the light threshold intensity at the rod-cone break point measured in $\log \mathrm{cd} / \mathrm{m}^{2}$;

(iii) final light threshold measured in $\log \mathrm{cd} / \mathrm{m}^{2}$; (iv) initial delay to detect the standard light stimuli, measured in minutes;

(v) time taken to reach the rod-cone break point, measured in minutes;

(vi) time taken to fully dark adapt, measured in minutes.

\section{Statistical analysis}

The statistical significance of differences in results between patients with PBC and control subjects was tested with the non-parametric heteroscedastic ' $t$-test'. Univariate (Spearman rank correlation, two-tailed test) analyses were performed between serum vitamin $A$, $\mathrm{RBP}, \beta$-carotene and the age of the patient together with the parameters of liver function, namely serum albumin and bilirubin. Further univariate analyses were then performed between the parameters of dark adaptation (that is the final light threshold value, time taken to initially detect light stimuli and to fully dark adapt) and the serum concentrations of vitamin A, RBP, $\beta$-carotene albumin and bilirubin and the age of the patient. Multivariate analyses were then performed on those parameters with significant univariate correlations by stepwise regression analysis.

Fisher's exact test was used to assess the discriminatory power of low serum vitamin A, RBP and $\beta$-carotene and raised bilirubin in the prediction of reduced light sensitivity in $\mathrm{PBC}$ patients.

Excel software version 5.0 (Microsoft Corporation, 1 Microsoft Way, Redmond, WA 98052-6399) and SSPS for Windows version 6.1 were used to analyse data. $p$ values of $<0.05$ were considered to be statistically significant.

\section{Ethical considerations}

The study was approved by the ethics committee of St James's Unversity Hospital.

\section{Results}

\section{Ophthalmic assessment}

In general all patients had good visual acuity $(6 / 9$ or greater). The lowest Snellen acuities were 6/18 in one patient with mild amblyopia and 6/12 in a further patient with early nuclear sclerosis. No patients had any Kayser-Fleischer-like corneal rings as previously described $^{10}$ or a significant colour vision deficit. One patient had punctate retinal pigment epithelial changes in both fundi similar to those described in vitamin A deficiency. ${ }^{11}$

\section{Dark adaptation}

Comparison of first and second eye testing

The mean \pm SEM dark adaptation curves for controls and patients are shown in Fig. 1, for the first (Fig. 1a) and second (Fig. 1b) eye tested. In control subjects there was no measurable difference in the dark adaptation curves of the first eye compared with the second eye tested. However, in patients with PBC early in the dark 


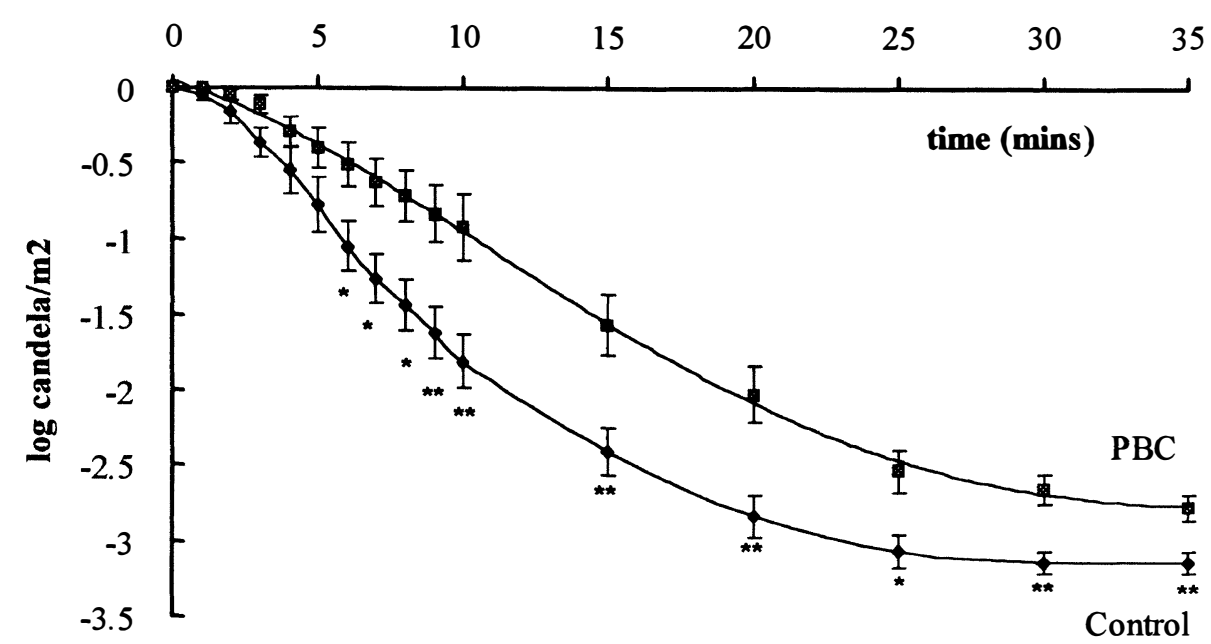

(a)

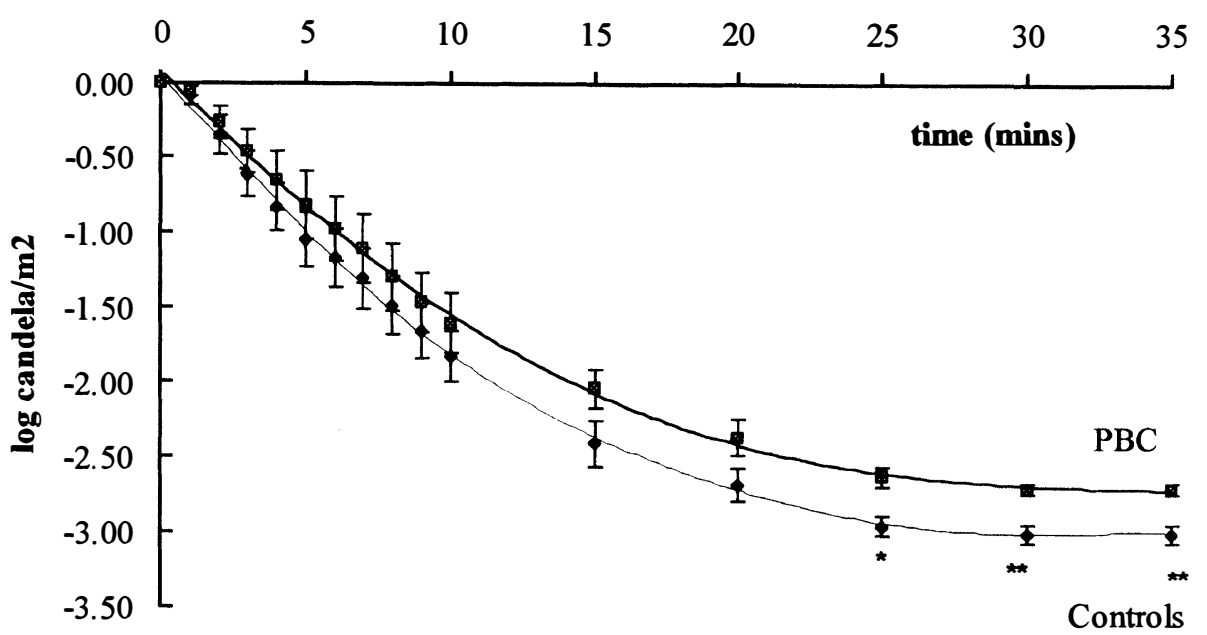

(b)

Fig. 1. Dark adaptation curves for controls and patients in the first (a) and second (b) eye tested. Mean values for light threshold at each time period are given with standard errors depicted by the bars. ${ }^{*} \mathrm{p}<0.03 ;{ }^{* *} \mathrm{p}<0.007$.

adaptation test period, the sensitivity to light stimuli was lower in the first eye compared with the second eye. Thus, at $15 \mathrm{~min}$ the mean light threshold was $-1.56 \pm 0.2$ $\log \mathrm{cd} / \mathrm{m}^{2}$ in the first eye compared with $-2.04 \pm 0.13$ $\log \mathrm{cd} / \mathrm{m}^{2}$ in the second eye, although this difference was not quite statistically significant $(p=0.06)$. However, final light threshold values at $35 \mathrm{~min}$ were similar in the two eyes $\left(-2.76 \pm 0.08\right.$ vs $\left.-2.70 \pm 0.04 \log \mathrm{cd} / \mathrm{m}^{2}\right)$. The results of the first eye tested were used for the data analysis and correlations as the dark adaptation curve for any one individual showed better separation of rod and cone components with a clear rod-cone break point in the first eye tested compared with the second eye tested. The difference in the dark adaptation curve for patients compared with controls was greater in the first eye tested as compared with the second eye tested.

\section{Light threshold}

As can be seen in Fig. 1a, in patients with PBC compared with controls, the sensitivity to light stimulus was impaired after 6 min of dark adaptation, the mean light threshold being $-0.51 \pm 0.15 \log \mathrm{cd} / \mathrm{m}^{2}$ compared with a control value of $-1.05 \pm 0.16 \mathrm{log} \mathrm{cd} / \mathrm{m}^{2}(p<0.03)$, the impaired light sensitivity being maintained in $\mathrm{PBC}$ patients thereafter, until completion of the dark adaptation measurements.

The data for the final light threshold in controls and patients are depicted in Fig. 2. There was considerable overlap in the distribution of data for final light threshold between the control and disease populations. The mean final light threshold of $-2.76 \pm 0.06 \mathrm{log} \mathrm{cd} / \mathrm{m}^{2}$ was $11.8 \%$ greater in patients with $\mathrm{PBC}$ compared with the mean control value of $-3.13 \pm 0.07 \mathrm{log} \mathrm{cd} / \mathrm{m}^{2}$ $(p<0.004)$, indicating that PBC patients had reduced sensitivity to low light illumination. Using the control population, an abnormally high final light threshold was defined as a value greater than $-2.7 \log \mathrm{cd} / \mathrm{m}^{2}(2$ standard deviations above the mean final light threshold for controls). Using this criterion three of the ten patients with PBC had abnormal dark adaptation. 


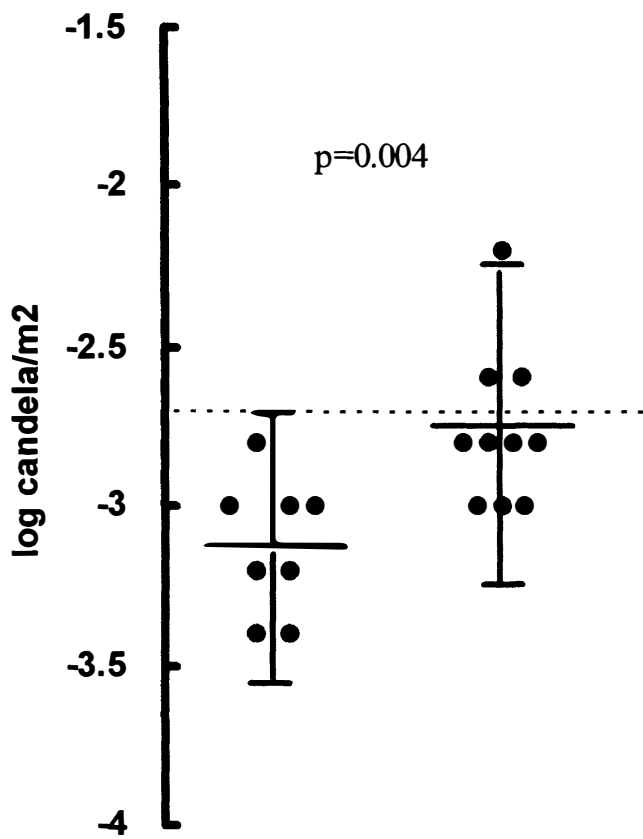

Fig. 2. The distribution of final light thresholds in controls (left) and patients (right). The individual data points are represented by the dots, with means and 2 standard deviations shown by the horizontal lines and bars respectively. The dotted line represents the cut-off above which the final threshold was judged to be abnormal (2 SD above the mean for the control group).

\section{Cone dark adaptation}

A clear rod-cone break point could be determined in all the PBC patients as shown for one individual in Fig. 3. Therefore, we were able to define a final cone light threshold and the time taken to reach the rod-cone break point. Unfortunately, in three of the control subjects the rod-cone break point was not clearly defined; thus cone dark adaptation data were available in only seven control subjects.

There was no significant difference in the final light threshold values for cone dark adaptation in patients $\left(-0.76 \pm 0.15 \mathrm{~cd} / \mathrm{m}^{2}\right)$ and controls $\left(-0.95 \pm 0.17 \mathrm{~cd} / \mathrm{m}^{2}\right.$; $p=0.41)$. The time taken to reach the rod-cone break point was longer in $\mathrm{PBC}$ patients $(10.1 \pm 0.76 \mathrm{~min})$ than controls $(7.3 \pm 1.0 \mathrm{~min})$, although this difference marginally failed to reach statistical significance $(p=0.053)$.

Time taken to detect initial light stimulus and fully dark-adapt

Patients with PBC took longer to detect the first light stimulus compared with the control subjects. In the first eye tested PBC patients took $3.0 \pm 0.6$ min compared with $1.9 \pm 0.5 \mathrm{~min}$ in controls. This difference was not statistically significant but the difference in times for the second eye tested was significant $(p<0.03)$, with times of $2.8 \pm 0.6$ vs $1.4 \pm 0.2 \mathrm{~min}$ in patients and controls respectively. The time taken to fully dark-adapt was similar in patients $(28.3 \pm 1.5 \mathrm{~min})$ and controls $(26.6 \pm 1.6 \mathrm{~min})$.

\section{Serum vitamin levels in PBC and final light threshold}

The laboratory data and dark adaptation final threshold values for individual patients are given in Table 1, with the distribution of data for vitamins $A$ and $E, \beta$-carotene and RBP shown in Fig. 4.

Two patients (patients 1 and 2) with abnormally high final light thresholds had low RBP concentrations $(<20 \mathrm{mg} / \mathrm{l})$ and low serum vitamin A concentrations $(<35 \mu \mathrm{g} / \mathrm{dl})$. Serum $\beta$-carotene was also low in patient 2 $(<25 \mu \mathrm{g} / \mathrm{dl})$ but within the normal range in patient 1 . Moreover, these two patients were the only patients studied who had a low serum albumin, and they also had the highest serum bilirubin values. In the third patient with a high final light threshold (patient 6) RBP, vitamin $A$ and $\beta$-carotene concentrations were all normal. Low RBP, vitamin A and $\beta$-carotene concentrations were observed in patient 3 , her final light threshold being at the bottom end of the normal range.

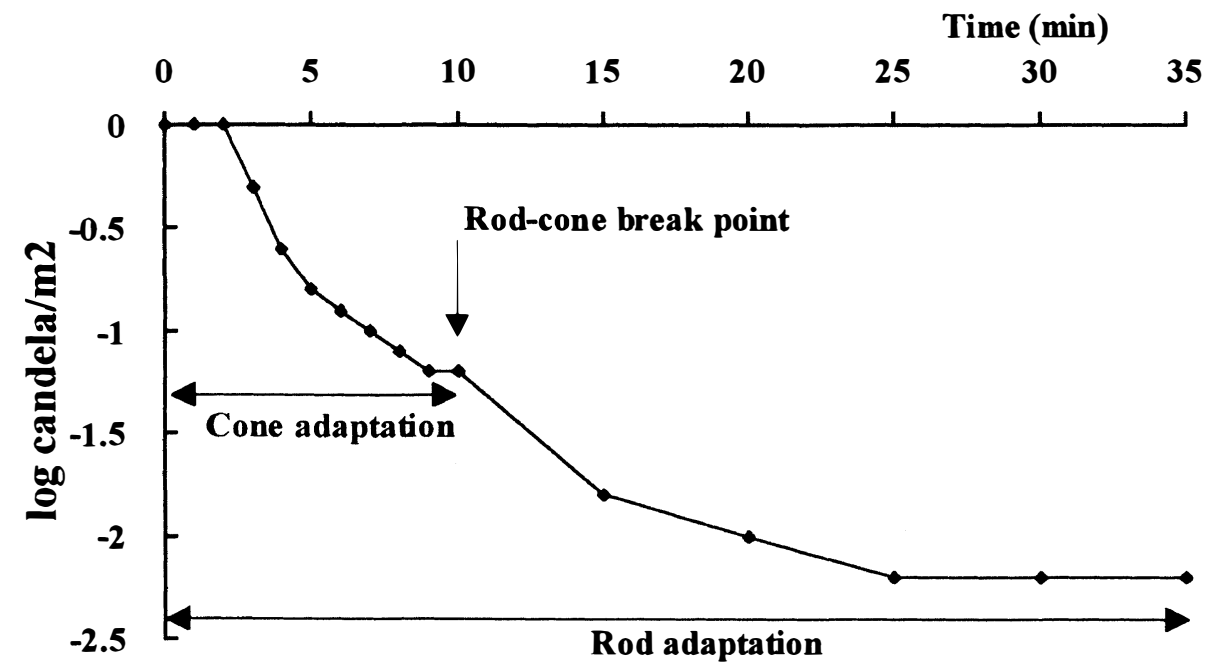

Fig. 3. An example of a dark adaptation curve from an individual with PBC demonstrating the cone adaptation curve, rod-cone break point and rod adaptation curve. 
Table 1. Final light threshold, liver biochemistry and vitamin-A-related compounds in $P B C$ patients

\begin{tabular}{cccccccc}
\hline Patient no. & Age $(\mathrm{yr})$ & $\begin{array}{c}\text { Final light threshold } \\
\left(\log \mathrm{cd} / \mathrm{m}^{2}\right)\end{array}$ & $\begin{array}{c}\text { Albumin } \\
(\mathrm{g} / \mathrm{l})\end{array}$ & $\begin{array}{c}\text { Bilirubin } \\
(\mu \mathrm{mol} / \mathrm{l})\end{array}$ & $\begin{array}{c}\beta \text {-carotene } \\
(\mu \mathrm{g} / \mathrm{dl})\end{array}$ & $\begin{array}{c}\text { Vitamin A } \\
(\mu \mathrm{g} / \mathrm{dl})\end{array}$ & $\begin{array}{c}\text { RBP } \\
(\mathrm{mg} / \mathrm{l})\end{array}$ \\
\hline $\mathbf{1}$ & 68 & -2.60 & 26 & 41 & 44.60 & 13.10 & 8.00 \\
$\mathbf{2}$ & 71 & -2.20 & 25 & 135 & 11.00 & 20.10 & 11.00 \\
$\mathbf{3}$ & 61 & -2.80 & 41 & 23 & 22.00 & 22.40 & 18.00 \\
$\mathbf{4}$ & 45 & -3.00 & 42 & 5 & 78.70 & 35.60 & 20.00 \\
$\mathbf{5}$ & 76 & -2.80 & 43 & 11 & 92.60 & 49.80 & 24.00 \\
$\mathbf{6}$ & 74 & -2.60 & 37 & 24 & 72.40 & 47.50 & 31.00 \\
7 & 52 & -2.80 & 43 & 25 & 93.20 & 54.10 & 32.00 \\
$\mathbf{8}$ & 64 & -3.00 & 39 & 10 & 117.00 & 63.40 & 38.00 \\
9 & 65 & -2.80 & 34 & 8 & 20.80 & 73.30 & 43.00 \\
10 & 76 & -3.00 & 41 & 11 & 64.30 & 96.90 & 53.00 \\
\hline
\end{tabular}

Patient numbers in bold indicate those treated with vitamin A replacement therapy. Normal ranges: bilirubin, $0-17 \mu \mathrm{mol} / \mathrm{l}$, albumin, $37-49 \mathrm{~g} / \mathrm{l}$; vitamin A, 35-100 $\mu \mathrm{g} / \mathrm{dl} ; \mathrm{RBP}, 20-40 \mathrm{mg} / \mathrm{l} ; \beta$-carotene, $25-80 \mu \mathrm{g} / \mathrm{dl}$.

Patients 4 and 9 had low RBP and $\beta$-carotene concentrations respectively, but no abnormality of dark adaptation.

All patients with an abnormally low vitamin A concentration were receiving vitamin $\mathrm{A}$ supplementation. Overall, three of seven patients receiving vitamin A supplementation had a final light threshold $>2 \mathrm{SD} \log \mathrm{cd} / \mathrm{m}^{2}$ above the mean for the control population. The three patients not receiving vitamin A had normal vitamin A and RBP
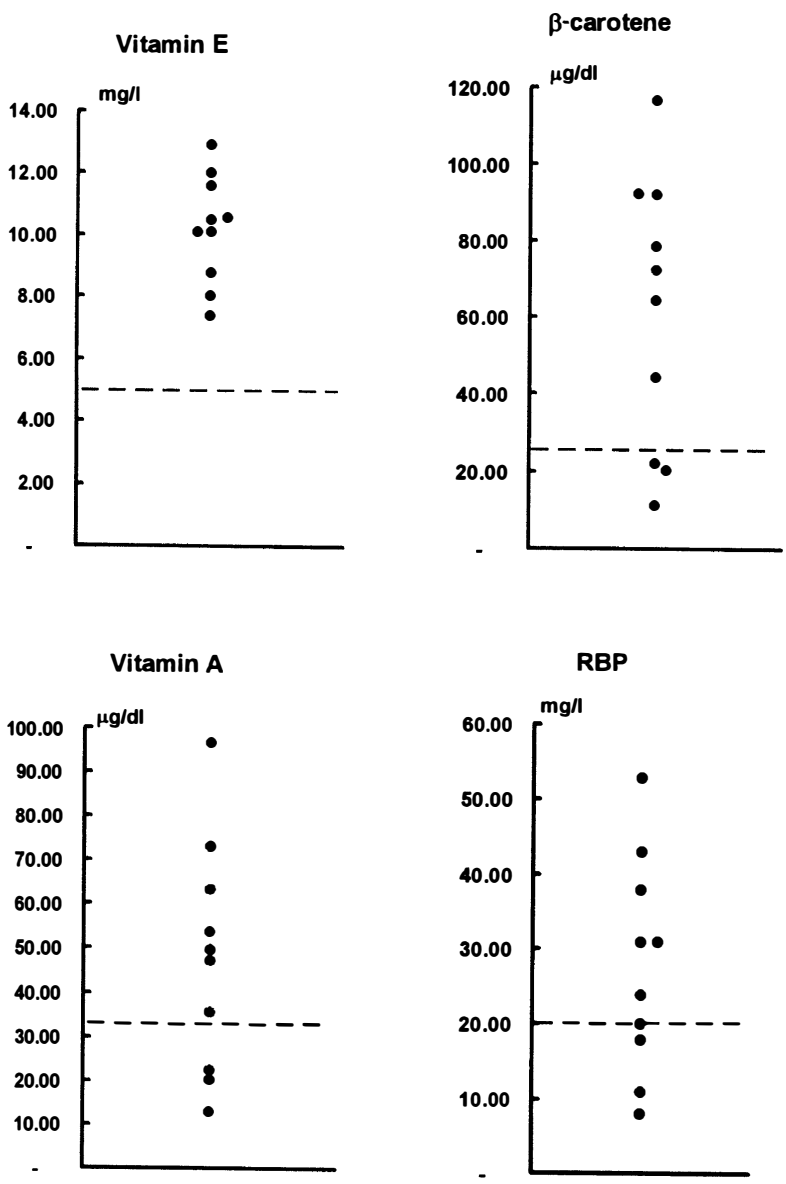

Fig. 4. The distribution of data for serum vitamin $A, \beta$-carotene, vitamin $A$ and retinol binding protein (RBP). The dots represent individual data points, with the dashed lines depicting the lower limit of the normal range. concentrations. All patients had vitamin E concentrations greater than $5 \mathrm{mg} / \mathrm{ml}$ (the lower limit of normal), the range being $8.0-12.9 \mathrm{mg} / 1$.

Raised bilirubin $(>17 \mu \mathrm{mol} / \mathrm{l})$, and low vitamin $A$, RBP or $\beta$-carotene concentrations did not predict those patients with impaired dark adaptation as determined by Fisher's exact test.

\section{Relationship between serum vitamin concentration, liver function and age}

The univariate analyses between serum vitamin concentration, liver function and age in patients are shown in Table 2. A strong positive correlation was seen between serum vitamin A and serum RBP concentration. However, no significant correlation was seen between serum vitamin $A$ and $\beta$-carotene. As serum bilirubin rose there was a fall in both serum vitamin A and RBP, although neither of these correlations was statistically significant. A significant positive correlation between serum $\beta$-carotene and albumin concentrations was observed.

\section{Dark adaptation and vitamin concentrations, age and liver function}

The univariate analyses between the parameters of dark adaptation and serum vitamin concentrations, liver function and age are shown in Table 3. The only parameter of dark adaptation to correlate significantly with serum vitamins, liver function or age was the final light threshold. A reduction in light sensitivity (i.e. a high

Table 2. Univariate analyses between serum vitamin-A-related compounds, liver function and age in $P B C$ patients

\begin{tabular}{lcrl}
\hline & Vitamin A & RBP & $\beta$-carotene \\
\hline RBP & $0.99^{* *}$ & & \\
$\beta$-carotene & 0.36 & 0.33 & \\
Bilirubin & -0.57 & -0.54 & -0.30 \\
Albumin & 0.35 & 0.28 & $-0.68^{*}$ \\
Age & -0.25 & -0.26 & -0.22 \\
\hline
\end{tabular}

Univariate analyses between serum vitamin A, RBP and $\beta$-carotene and (i) RBP, (ii) $\beta$-carotene, (iii) bilirubin, (iv) albumin and $(\mathrm{v})$ age. The $r$ value is given for each correlation. ${ }^{*} p<0.01 ;{ }^{* *} p<0.001$. 
Table 3. Univariate analysis between the parameters of dark adaptation, serum vitamin-A-related compounds, liver function and age in patients

\begin{tabular}{lccc}
\hline $\begin{array}{l}\text { Parameter of } \\
\text { dark adaptation }\end{array}$ & $\begin{array}{c}\text { Final light } \\
\text { threshold }\end{array}$ & $\begin{array}{c}\text { Time to detect } \\
\text { light stimuli }\end{array}$ & $\begin{array}{c}\text { Time to fully } \\
\text { dark-adapt }\end{array}$ \\
\hline Vitamin A & $-0.64^{*}$ & -0.50 & -0.30 \\
RBP & -0.60 & -0.48 & -0.33 \\
B-carotene & -0.54 & -0.24 & 0.14 \\
Bilirubin & $0.81^{* *}$ & 0.10 & 0.10 \\
Albumin & -0.59 & -0.28 & 0.21 \\
Age & $0.67^{*}$ & 0.61 & 0.39 \\
\hline
\end{tabular}

Univariate analyses between final light threshold, times to detect light stimuli and to fully dark-adapt and (i) RBP, (ii) $\beta$-carotene, (iii) bilirubin, (iv) albumin, (v) vitamin A and (vi) age. The $r$ value is given for each correlation. ${ }^{*} p<0.01 ;{ }^{* *} p<0.001$.

final light threshold) was strongly correlated with bilirubin, increasing age and low serum vitamin A concentration.

Stepwise multiple regression analysis demonstrated that only age $(p<0.05)$ and serum bilirubin $(p<0.001)$ were significant determinants of final light threshold.

\section{Discussion}

The present study demonstrates that dark adaptation is impaired in patients with early PBC compared with agematched controls. However, most of our patients had been receiving intramuscular vitamin $\mathrm{A}$ and abnormal dark adaptation was found in only $30 \%$ of patients. Our findings confirmed some ${ }^{12}$ but not all studies. ${ }^{1,4}$ Indeed, Herlong et al. ${ }^{4}$ documented abnormal dark adaptation in 9 of 11 patients with PBC whilst Shepherd and colleagues ${ }^{1}$ found no evidence of abnormal dark adaptation in 9 PBC patients who were vitamin-Adeficient. The reasons for the different results found in the present study compared with others ${ }^{1,4}$ may be: (i) lack of age-matched control groups, (ii) severity of PBC disease, (iii) the definition of abnormal dark adaptation and (iv) vitamin A supplementation in our patients.

We found that as age increased in PBC patients, there was an associated rise in final light threshold. A similar but not quite significant correlation $(r=0.59 ; p=0.07)$ between age and final light threshold was also seen in the control group. Thus, age-matching between controls and patients is important when comparing dark adaptation in different cohorts.

Patients in the present study were deliberately selected as those with early PBC. Indeed, only two of 10 patients had more advanced liver disease of Child-Pugh class B compared with 11 of 25 patients in Shepherd and co-workers' study ${ }^{1}$ who were class B and C. In Herlong et al.'s cohort ${ }^{4}$ the mean serum bilirubin of patients was $88 \pm 29 \mu \mathrm{mol} / 1 \mathrm{compared}$ with $29 \pm 12 \mu \mathrm{mol} / 1$ in the current study. The early stage of disease may account for the low frequency of ocular abnormalities previously described, such as Kayser-Fleischer rings, ${ }^{10}$ retinal lesions, peripheral field constriction and colour vision abnormalities. ${ }^{11}$
The dark adaptation curves were different in the first and second eye tested. Indeed the difference between patients and controls was more marked in the first eye compared with the second eye examined. The asymmetry between the two eyes can be explained by the inherent nature of the dark adaptation protocol used in the current study. Since subjects will have entered the dark adaptation room from a lighted area, the first eye tested will have been partially bleached. Furthermore, the second eye tested will have become better darkadapted compared with the first eye as this eye had been covered by an eye patch prior to bleaching. This hypothesis was supported by the observation that in one control subject the dark adaptation response when repeated for the first eye was similar to that in the second eye tested. However, using the current protocol we would suggest that the first eye tested is more likely to reveal differences in the complex interactions that influence dark adaptation and thus detect those patients with abnormal dark adaptation who may require vitamin A supplementation.

In this study, final light threshold was the best determinant of impaired dark adaptation. Herlong and colleagues ${ }^{4}$ defined impaired dark adaptation in subjects with an average age of 51 years as a final light threshold of greater than $-4.6 \log \mathrm{cd} / \mathrm{m}^{2}$. This study did not use age-matched controls. If we had adopted this criterion, all our patients and controls would have had impaired dark adaptation. We chose a value for abnormal dark adaptation 2 SD above the mean for the age-matched control group. Furthermore dark adaptation was assessed in Herlong's study using a Goldman-Weekers adaptometer as opposed to the Friedman adaptometer used in the current study. There may be a different spectral composition between the Friedman and Goldman-Weekers adaptometers that means the comparison of the photopic 'candela' units used in the present study and in Herlong et al.'s study is difficult to make with any degree of validity. Therefore patients in the present study had earlier PBC and more stringently defined criteria for abnormal dark adaptation which, together with different methodology, may account for the lower prevalence of defective dark adaptation compared with Herlong's study. ${ }^{4}$ Differences in the definition of dark adaptation may also account for others ${ }^{1}$ not finding any patients with impaired dark adaptation.

Vitamin A is required for normal rod function and thus for night vision. We observed a strong inverse correlation between serum vitamin A concentration and final light threshold, confirming the importance of vitamin $A$ in the maintenance of night vision. Deficiency of vitamin $A$ in patients with $\mathrm{PBC}$ may result from malabsorption due to chronic cholestasis with impaired bile acid production. ${ }^{13,14}$ Indeed there was an inverse correlation between vitamin $\mathrm{A}$ and serum bilirubin, although this was not significant in the small numbers studied and the narrow range of disease severity. Kaplan et $a{ }^{2}{ }^{2}$ in a study of 52 patients observed an inverse relationship between vitamin $\mathrm{A}$ and serum bilirubin. 
This suggests that as hepatic function declines, vitamin A deficiency becomes more likely. Alternative explanations for vitamin A deficiency in PBC include reduced hepatic vitamin storage capacity or impaired synthesis of vitamin A transport proteins such as RBP. ${ }^{15,16}$ The strong positive correlation between serum vitamin $A$ and $R B P$ is unsurprising since RBP is responsible for the mobilisation of vitamin A from the liver. ${ }^{17}$ As hepatic function decreases, there is reduced production of $\mathrm{RBP}^{18}$ and thus reduced mobilisation of hepatic vitamin $\mathrm{A}$ leading to low serum vitamin A concentrations and low delivery of vitamin A to the tissues. It is at least theoretically possible that, regardless of the amount of vitamin A given, a deficiency of RBP may limit the serum level of vitamin A.

Only three patients in our cohort had vitamin A deficiency, as defined by serum vitamin A concentrations below the normal range. All three of these patients had been treated with standard dose vitamin A therapy. This low prevalence of vitamin A deficiency compared with other studies ${ }^{1,2,4}$ may be due to the early disease stage of our patients or the use of prophylactic vitamin A replacement therapy. Two of the three patients with abnormal dark adaptation were vitamin-A-deficient, despite vitamin A replacement therapy highlighting the need for monitoring. However, the third patient had no evidence of vitamin A deficiency. We speculate that defective dark adaptation in this case may have been due to zinc deficiency, ${ }^{19}$ since a zinc-containing metalloenzyme is needed to convert retinol to its biologically active form retinaldehyde. Zinc deficiency has been demonstrated in patients with alcoholic cirrhosis $^{20,21}$ and PBC. ${ }^{4}$

Vitamin A supplementation is useful in the reversal of impaired dark adaptation. ${ }^{4,22}$ For a number of years all our patients presenting with $\mathrm{PBC}$ have been recommended to receive monthly intramuscular injections of vitamin $\mathrm{A}$. In the event not all receive vitamin A. However, vitamin A supplementation for all patients with $\mathrm{PBC}$ may be unnecessary since vitamin $\mathrm{A}$ deficiency has been reported to be uncommon in PBC. ${ }^{12}$ Furthermore vitamin A therapy, in modest oral doses of 20000 to $45000 \mathrm{IU} /$ day has been associated with hepatotoxicity. ${ }^{23-25}$ In the present study, high final light thresholds were closely correlated by multivariate analysis with high serum bilirubin and (to a lesser extent) older age, rather than serum vitamin A concentrations alone. This suggests that older patients with worsening jaundice may be at greatest risk of impaired night vision. We therefore suggest that vitamin A therapy should be targeted especially at these patients, who ideally should undergo dark adaptation studies and serum vitamin A assays before and after embarking on vitamin A supplementation.

In conclusion, patients with early $\mathrm{PBC}$ have impaired dark adaptation, which is abnormal in $30 \%$ of patients even with the usual vitamin A treatment. Thus, although vitamin A supplementation does reverse impaired dark adaptation, ${ }^{4,22}$ within 8 days, ${ }^{26}$ conventional recommended dose regimes may be inadequate or ineffective. Abnormal dark adaptation is closely related to low serum vitamin A concentrations, raised serum bilirubin and increased age, the latter two being the most important determinants of impaired dark adaptation, although zinc levels may also be important. We therefore recommend that vitamin A supplementation, preferably by the oral route, ${ }^{3}$ should be commenced in older patients as clinical jaundice becomes apparent.

Moreover, where the facility to measure dark adaptation is available then the appropriate dose of vitamin A should be titrated against the dark adaptation response. However, we would recommend caution in the use of vitamin A supplementation in all patients with early PBC since the magnitude of dark adaptation impairment is modest in these patients and would not be expected to have a significant effect on the patient's visual function.

The authors are indebted to Mr W. Amoaku, Mr C. Diaper, Miss A. Tan-yee and Dr P. Harvey for contributing to the inception of this study.

\section{References}

1. Shepherd AN, Bedford GJ, Hill A, Bouchier IAD. Primary biliary cirrhosis, dark adaptometry, electro-oculography, and vitamin A state. BMJ 1984;289:1484-5.

2. Kaplan MM, Elta GH, Furie B, Sadowski JA, Russell RM. Fatsoluble vitamin nutriture in primary biliary cirrhosis. Gastroenterology 1988;95:787-92.

3. Walt RP, Kemp CM, Lyness L, Bird AC, Sherlock S. Vitamin A treatment for night blindness in primary biliary cirrhosis. BMJ 1984;288:1030-1.

4. Herlong HF, Russell RM, Maddrey WC. Vitamin A and zinc therapy in primary biliary cirrhosis. Hepatology 1981;1:348-51.

5. Sherlock S. Primary biliary cirrhosis: critical evaluation and treatment policies. Scand J Gastroenterol 1982;(Suppl 77):63-74.

6. Scheuer PJ. Liver biopsy interpretation. 2nd ed. Baltimore: Williams and Wilkins, 1973.

7. Pugh RN, Murray-Lyon IM, Dawson JL, Pietroni MC, Williams R. Transection of the oesophagus for bleeding oesophageal varices. Br J Surg 1973;60:646-9.

8. Stewart WK, Fleming LW. Plasma retinol and retinol binding protein concentration in patients on maintenance haemodialysis with and without vitamin A supplements. Nephron 1982;30:15-21.

9. Maraini G, Fadda G, Gozzoli F. Serum levels of retinolbinding protein in different genetic types of retinitis pigmentosa. Invest Ophthalmol 1975;14:236-7.

10. Fleming CR, Dixon ER, Wahner HW, Hollenhorst RW, McCall TT. Pigmented corneal rings in non-Wilsonian liver disease. Ann Intern Med 1977;86:285-8.

11. Grey RHB. Visual field changes following hepatic transplantation in a patient with PBC. Br J Ophthalmol 1991;75:377-80.

12. Barber C, Brimlow G, Galloway NR, Toghill P, Walt RP. Dark adaptation compared with electrooculography in primary biliary cirrhosis. Doc Ophthalmol 1989;71:397-402.

13. Lanspa SJ, Chan AT, Bell JS III, Go VL, Dickson ER, DiMagno EP. Pathogenesis of steatorrhea in primary biliary cirrhosis. Hepatology 1985;5:837-42.

14. Ros E, Garcia-Puges A, Reixach M, Cuso E, Rodes J. Fat digestion and exocrine pancreatic function in primary biliary cirrhosis. Gastroenterology 1984;87:180-7.

15. Leevy FR, Goodman DS. Vitamins and liver injury. Am J Clin Nutr 1970;23:493-8. 
16. Smith FR, Goodman DS. The effects of liver, thyroid and kidneys on the transport of vitamin A in human plasma. J Clin Invest 1971;50:2426-36.

17. Nyberg A, Berne B, Nordlinder H, Busch C, Eriksson U, Loof $\mathrm{L}$, et al. Impaired release of vitamin A from liver in primary biliary cirrhosis. Hepatology 1988;8:136-41.

18. Goodman DS. Plasma retinol-binding protein. Ann N Y Acad Sci 1980;348:378-90.

19. Raskin NH, Slaigar KP, Steinberg RH. Dark adaptation slowed by inhibitors of alcohol dehydrogenase in the albino rat. Brain Res 1973;50:496-500.

20. Walker BE, Dawson JB, Kelleher J, Losowsky MS. Plasma and urinary zinc in patients with malabsorption syndromes or hepatic cirrhosis. Gut 1973;14:943-8.

21. Morrison SA, Russell RM, Carney EA, Oaks EV. Zinc deficiency: a cause of abnormal dark adaptation in cirrhotics. Am J Clin Nutr 1978;31:276-81.
22. Russell RM, Morrison SA, Smith FR, Oaks EV, Carney EA. Vitamin-A reversal of abnormal dark adaptation in cirrhosis: study of effects on the plasma retinol transport system. Ann Intern Med 1978;88:622-6.

23. Minuk GY, Kelly JK, Hwang WS. Vitamin A hepatotoxicity in multiple family members. Hepatology 1988;8:272-5.

24. Hathcock JN, Hattan DG, Jenkins MY, McDonald JT, Sundaresan PR, Wilkening VL. Evaluation of vitamin A toxicity. Am J Clin Nutr 1990;52:183-202.

25. Guarascio P, Portmann B, Visco G, Williams R. Liver damage with reversible portal hypertension from vitamin $\mathrm{A}$ intoxication: demonstration of Ito cells. J Clin Pathol 1983;36:769-71.

26. Kemp CM, Jacobson SG, Faulkner DJ, Walt RW. Visual function and rhodopsin levels in humans with vitamin A deficiency. Exp Eye Res 1988;46:185-97. 